\title{
The environment in childhood and risk of motor neuron disease
}

\author{
C N Martyn, C Osmond
}

\begin{abstract}
To investigate a possible link between subclinical infection with poliovirus in childhood and increased risk of motor neuron disease in adult life, environmental determinants of infection in early life were compared in 98 cases of motor neuron disease and 335 age and sex matched controls. A weak but consistent relation was found between motor neuron disease and factors in the childhood environment known to increase likelihood of enteric infection. Relative risks associated with spending the first 10 years of life in a house without domestic amenities such as a bathroom, running hot water or flushing lavatory, living in overcrowded conditions, frequent changes of address or having a sibling with paralytic poliomyelitis were all greater than unity, although only those for absence of running hot water and frequent changes of address were statistically significant.
\end{abstract}

(尹 Neurol Neurosurg Psychiatry 1992;55:997-1001)

In England and Wales the current geographical distribution of mortality from motor neuron disease correlates closely with the pattern of notifications of poliomyelitis in the past. ${ }^{1}$ There are also similarities in the time trends of the two diseases. The steady rise in mortality from motor neuron disease seen in Europe, Scandinavia and North America over the past 25 years ${ }^{1-4}$ has paralleled the increase in incidence of poliomyelitis that occurred in the same countries during the first half of the century. These epidemiological data suggest that there might be a causal relationship between the two conditions. Although evidence from case series suggests that a history of paralytic poliomyelitis can be obtained from patients with motor neuron disease more often than could be expected by chance alone, ${ }^{56}$ it is clear that most patients cannot recall ever having had poliomyelitis. Any link therefore, must be with subclinical infection with poliovirus rather than with poliomyelitis itself.

It is possible that subclinical forms of poliovirus infection exist in humans, ${ }^{17}$ as have been shown in primates, ${ }^{8}$ in which the infection involves the central nervous system but is not severe enough to cause muscle weakness. Although these subclinical cases would never have been diagnosed as having poliomyelitis, considerable loss of motor neurons could have occurred. Left with a depleted population of motor neurons, such individuals would be especially vulnerable to further neuronal loss, perhaps through ageing or because of a second insult to the nervous system.

A prediction from this hypothesis is that risk of motor neuron disease will be related to factors that determine likelihood of poliovirus infection in childhood and the age at which it occurs. The prevalence of seropositivity to poliovirus in the middle aged and elderly is high ${ }^{9}$ partly because exposure to wild type virus during the first half of the century was common and partly as a result of programmes of active immunisation against the virus. Unfortunately, serological techniques do not distinguish between those who acquired antibodies as a result of infection with wild type virus and those who are seropositive because they have been immunised; they cannot therefore be used to estimate childhood exposure to poliovirus retrospectively. Population-based surveys carried out in the $1950 \mathrm{~s},{ }^{10-12}$ however, before mass immunisation programmes were instituted, identified the important environmental determinants of poliovirus infection as the presence or absence of domestic amenities such as running hot water, flushing lavatories and bathrooms, degree of domestic overcrowding and social class.

We present the results of a case control study designed to investigate whether these variables were associated with risk of motor neuron disease.

\section{Patients and methods}

We attempted to recruit all prevalent cases of motor neuron disease resident in the area served by the Wessex Regional Health Authority. To achieve as complete ascertainment of cases as possible, several different methods were used to identify individuals with the disease. Principal sources of information were the case records of the Wessex Neurological Centre, Southampton General Hospital, a diagnostic register maintained by the clinical neurophysiology department of the Wessex Neurological Centre and a list of members of the Motor Neuron Disease Association whose addresses corresponded to the geographical area of the study. All patients included in the study as cases had been seen by a consultant neurologist and all diagnoses were checked by reviewing the original case records or, for the few cases where this was not possible, by writing to the neurologist whose care the patient was under. Minimum diagnostic criteria were clinical or electrophysiological signs 
of both upper and lower motor neuron disease and that both brainstem and at least one region of the spinal cord were affected. In addition, evidence was required of progression of disease over time. Cases who showed atypical clinical features or in whom the diagnosis was doubtful were not entered into the study. To avoid any confusion with cases of late degeneration after poliomyelitis, any subject whose medical records indicated that they had suffered from poliomyelitis in the past or who, when interviewed, gave a history of acute paralytic poliomyelitis was excluded.

In the later stages of the study, when it became clear that insufficient numbers of cases could be identified within the area defined above, we recruited patients from contiguous district health authorities outside the Wessex health region who were under the care of neurologists in Bristol, Gloucester and Oxford. The same criteria for diagnosis were applied.

For each case, six potential controls, matched for sex and within the same five year age band as the case (40-44, 45-49, 50-54 etc), were selected from the list of the general practitioner. who had originally referred the case for investigation. The list of patients registered with the general practitioner was searched forward from the entry for the case and the first six eligible controls were identified.

After obtaining permission from the general practitioner, patients and the first four controls selected for each case, were sent a letter requesting permission for an interviewer to call. Those who failed to respond were contacted by a personal visit. Where fewer than three controls agreed to be interviewed, the remaining two controls were approached in the same way. The interviewer administered a questionnaire enquiring about the subject's domestic, social and family circumstances during the first 10 years of their life. All interviews, both of patients and controls, were carried out by the same person.

From the various sources described above, 223 possible cases of motor neuron disease were identified. Of these, 77 had died by the time we made contact with the general practitioner. In 21 cases the diagnosis was either not confirmed as motor neuron disease or there was an indication in the case records that the patient had previously suffered an attack of acute paralytic poliomyelitis. Eleven patients had moved from the area of the study and no attempt was made to trace them further. Six proved to be duplicates. There were thus 108 cases eligible for recruitment into the study: in three cases we were refused permission to approach the patient by the general practitioner; six declined to take part after receiving a letter explaining the study and one case was later excluded because she gave a history of paralytic poliomyelitis during the interview. The results presented here were therefore obtained from 98 cases who were successfully interviewed.

In total, 610 subjects were selected as controls from general practice lists. Of these, 108 proved to be untraceable, either because the recorded address was no longer current or because they had died. Of the 502 who were sent a letter explaining the study and requesting permission for an interviewer to visit, 167 declined to take part. Interviews were obtained from 335 subjects-a response rate of $67 \%$. For three cases we did not succeed in interviewing three or more matched controls; each of these cases was matched with two controls. Three controls from whom interviews had been obtained were excluded from the analysis because they were matched to the case who, during the interview, gave a history of poliomyelitis.

Demographic characteristics of the cases in this study were fairly typical of patients with motor neuron disease in the UK: $61 \%$ were men; median age at the time of interview was 62 years (range 32-84); and all were white. No case gave a family history of motor neuron disease.

The method used for matching controls by age proved satisfactory; $86 \%$ of controls were within two years of age of the case and there was no systematic tendency for controls to be older or younger than cases.

Analysis of the data was carried out using conditional logistic regression techniques to take account of the matching of cases and controls. ${ }^{13}$ Results have generally been presented as an odds ratio as an estimate of relative risk.

\section{Results}

There was a consistent relation between both the absence of domestic amenities and overcrowding within the home during the first 10 years of life and risk of motor neuron disease. Odds ratios associated with the lack of a room with a fixed bath, lack of a running hot water system, lack of an indoor flushing lavatory and domestic crowding of 1.5 persons per bedroom or more were all greater than unity when compared with the presence of these amenities or a lesser degree of crowding. None of these odds ratios was large and only that for lack of a hot water system was statistically significant. These results are shown in table 1.

No relation was found between social class at birth (assessed by father's occupation), size of family, educational level (assessed by age at which the subject ceased full time education), or the size of the town lived in and risk of motor neuron disease (table 2).

Subjects who changed address more than three times in the first 10 years of life had a higher relative risk of motor neuron disease (table 2) than subjects who moved less often or remained in the house in which they were born. This increased risk persisted after adjustment in a multiple regression model for absence of domestic amenities and crowding.

Subjects with a sibling who had suffered from paralytic poliomyelitis had an increased relative risk of motor neuron disease. The risk was higher in those who recalled that the affected sibling was living in the same house at the time of infection (table 3 ). No association was found with other infectious diseases of 
Table 1 Relative risk of motor neuron disease according to domestic conditions in the first home. (Each variable analysed individually)

\begin{tabular}{llll}
\hline & $\begin{array}{l}\text { Numbers of } \\
\text { cases exposed }\end{array}$ & $\begin{array}{l}\text { Odds } \\
\text { ratio }\end{array}$ & $95 \%$ CI \\
\hline No room with fixed bath & 59 & 1.2 & 0.8 to 2.0 \\
No running hot water & 69 & 1.8 & 1.1 to 3.0 \\
No indoor WC & 59 & 1.4 & 0.9 to 2.2 \\
Crowding - $\geq 1 \cdot 5$ /bedroom & 60 & 1.4 & 0.9 to 2.2
\end{tabular}

Table 2 Relative risk of motor neuron disease associated with indicators of living conditions in childhood. (Each variable analysed individually)

\begin{tabular}{llll}
\hline & $\begin{array}{l}\text { Numbers of } \\
\text { cases exposed }\end{array}$ & $\begin{array}{l}\text { Odds } \\
\text { ratio }\end{array}$ & 95\% CI \\
\hline $\begin{array}{l}\text { Social class of father } \\
\quad \text { III, IV, V compared with I and II) }\end{array}$ & 69 & 0.7 & 0.4 to 1.4 \\
$\begin{array}{l}\text { Number of siblings } \\
\quad(0 \text { or 1 compared with 2 or more) }\end{array}$ & 30 & 1.1 & 0.7 to 1.9 \\
$\begin{array}{l}\text { Age at leaving school } \\
\quad(\leq 14 \text { years compared with > 14 years) }\end{array}$ & 47 & 1.3 & 0.8 to 2.2 \\
$\begin{array}{l}\text { Size of town } \\
\quad \text { (Large town compared with small town or village) }\end{array}$ & 46 & 1.0 & 0.6 to 1.5 \\
$\begin{array}{l}\text { More than 3 changes of house before } \\
\text { age of } 10 \text { years }\end{array}$ & 12 & 2.6 & 1.2 to 5.6 \\
\hline
\end{tabular}

Table 3 Relative risk of motor neuron disease associated with recall of infection in childhood. (Each variable analysed individually)

\begin{tabular}{lccl}
\hline & $\begin{array}{l}\text { Numbers of } \\
\text { cases exposed }\end{array}$ & $\begin{array}{l}\text { Odds } \\
\text { ratio }\end{array}$ & $95 \%$ CI \\
\hline Sibling with paralytic poliomyelitis & 5 & 1.9 & 0.6 to 5.8 \\
Sibling with paralytic poliomyelitis & 2 & 4.4 & 1.2 to 16.6 \\
$\quad$ living in the same household & 75 & 0.6 & 0.3 to 1.3 \\
Measles & 12 & 1.2 & 0.6 to 2.3 \\
Scarlet fever & 4 & 0.6 & 0.2 to 1.7 \\
Diphtheria & 62 & 0.8 & 0.7 to 1.3 \\
Chicken pox & 5 & 2.3 & 0.8 to 7.3 \\
Rheumatic fever & & & \\
\hline
\end{tabular}

childhood.

Because of the range of ages of the subjects in the study, the time during which they were children spanned most of the first half of this century. During this period considerable changes both in domestic conditions and rates of infection occurred. We investigated whether the strength of the observed associations between risk of motor neuron disease and possession of domestic amenities, domestic overcrowding, frequency of moving house and experience of childhood infections varied with the age of the subjects. No such effect was seen. Attempts to examine the effect of these factors in combination, using multiple regression analysis, were unsuccessful because many of the variables were highly correlated.

\section{Discussion}

The results of this case-control study show a weak but consistent association between risk of motor neuron disease and factors in the childhood domestic environment that are known to increase rates of infection with poliovirus. Absence of a room with a fixed bath, lack of running hot water and lack of an inside flushing lavatory in the house lived in during the first 10 years of childhood were all individually associated with an increase in risk of motor neuron disease, although of these, only the increased risk associated with lack of running hot water was statistically significant. There were also increases in relative risk with a measure of overcrowding within the home and with frequent changes of address during the first 10 years of life. These two factors are known to be linked to higher rates of infection in childhood. ${ }^{14}{ }^{15}$ There was also a suggestion, though numbers were very small, that risk of motor neuron disease was higher in those who recalled having a sibling with poliomyelitisespecially if he or she had been living in the same house at the time of the infection.

We were forced to use indirect indicators of past exposure to poliovirus because serological techniques are unable to distinguish between those who have acquired antibodies to poliovirus because of previous infection with wild type virus and those who have been actively immunised. The results of the study rely on the subject's recall of the conditions under which he or she was brought up and it is inevitable that lapses in memory will have led to inaccuracies in the information that was obtained. Since the subjects were unaware of the hypothesis being tested, we do not think it likely that there would have been systematic differences in the quality of recall between cases and controls. This source of error could therefore be expected to obscure, rather than enhance, any relationship between the variables measured and risk of motor neuron disease and to bias the odds ratio towards unity.

The response rate in controls was lower than that for cases; only $67 \%$ of the control subjects approached agreed to be interviewed whereas we were able to obtain completed questionnaires from $92 \%$ of eligible cases. The factors that led subjects to decide not to take part in the study are unknown but it seems unlikely that they were closely related to the conditions in which they spent their childhood. The possibility that a bias was introduced by differences in response rates cannot be excluded.

The likelihood of the central nervous system being affected by poliovirus is highly dependent on the age at which infection occurs. Infection in childhood, adolescence or adult life leads to neurological disease very much more frequently than infection during infancy. If poliovirus is involved in the aetiology of motor neuron disease, cases of motor neuron disease should have spent their childhood in an environment in which first exposure to poliovirus would have been delayed beyond the relatively safe period of infancy. We have previously suggested that such an environment would have been characterised by good social and domestic circumstances. ${ }^{1}$ In fact, the results of this study showed quite the opposite; cases of motor neuron disease were more likely to have spent their childhood in poor circumstances.

Although we stand by the prediction that cases of motor neuron disease would have spent their childhood in conditions associated with delayed exposure to poliovirus, we now believe that our former suggestions about the 
sort of conditions that led to delayed exposure were wrong. Population studies in Scotland, Northern Ireland and the USA in the 1950s showed that most children, regardless of social class or the domestic conditions in which they lived, first became seropositive to poliovirus some time after the first year of life. ${ }^{10-12}$ So, even those children living in poor conditions first encountered poliovirus at an age when they would have been vulnerable to its neurotropic effects.

The prevalence of seropositivity, however, was lower at all ages in those living in good social conditions and it is probable that between 10 and $20 \%$ of children escaped infection altogether. If the hypothesis linking poliovirus with motor neuron disease is right, these individuals who never encountered poliovirus will be at lower risk of motor neuron disease. A good domestic environment in childhood should therefore be associated with a reduced risk of the disease.

The environmental factors associated with increased likelihood of poliovirus infection at a vulnerable age are not unique to that microorganism. They also indicate an increased risk of other infections transmitted by the faecaloral route. By themselves, the results presented here cannot be interpreted as implicating poliovirus in the causation of motor neuron disease. But we suggest that the results of this study should be considered in combination with what is already known about the relation between motor neuron disease and poliovirus infection. The geographical correlation between mortality from motor neuron disease and past poliomyelitis is remarkable for its specificity. No other notifiable infectious disease correlates as strongly. ${ }^{1}$ There is also evidence from case series that a history of paralytic poliomyelitis can be obtained from patients with motor neuron disease more often than could be expected from a chance association of the two diseases. ${ }^{56}$ No significant association between the two diseases has ever been found in case-control studies ${ }^{16-18}$ but the very small numbers of subjects reporting poliomyelitis in these studies limit the interpretation of these negative findings.

The types of neurons that are predominantly affected-the first and second order motor neurons - are the same in both diseases. The clinical picture of acute paralytic poliomyelitis is, of course, dominated by lower motor neuron signs, whereas patients with motor neuron disease typically show signs of upper motor neuron involvement. But pathological studies, both of fatal cases in humans and of experimental poliomyelitis in primates, show that the distribution of lesions extends beyond the grey matter of the anterior horn of the spinal cord. The posterior and intermediate columns of grey matter, the substantia gelatinosa, the brainstem-including the thalamus and hypothalamus, the nuclei of the cerebellum and the motor areas of the cerebral cortex are also affected. Further, the distribution of lesions in the brain is essentially the same in nonparalytic cases as it is in symptomatic cases, although there is great individual variation in severity. ${ }^{8}$

What pathogenetic mechanism could link subclinical infection with poliovirus to the later development of motor neuron disease? There was no evidence of continuing poliovirus infection in a case of motor neuron disease with antecedent poliomyelitis ${ }^{19}$ and attempts to demonstrate poliovirus-related RNA or DNA sequences in the central nervous system or an increase in cell-mediated immunity to poliovirus in patients with motor neuron disease have produced conflicting results. ${ }^{20-23}$ But lack of evidence of persistence or latency does not preclude an aetiological role for poliovirus. As was pointed out in the introduction, infection with the virus, even if subclinical, might lead to loss of motor neurons and increased susceptibility to the attrition of these neurons that is known to occur with increasing age. ${ }^{24}$

Previous epidemiological investigations of motor neuron disease have largely been focused on events in adult life. They have not consistently identified any strong risk factors for the disease. ${ }^{16-1825-27}$ The results of this study suggest that cases of motor neuron disease spent their childhood in conditions associated with an increased risk of enteric infection. They are compatible with, although they do not provide strong direct support for, the hypothesis that poliovirus, or a microorganism that is transmitted in a similar way, is involved in the aetiology of motor neuron disease. They also suggest that the initial events in the chain of causation that leads to motor neuron disease occur in early life.

We are grateful to Drs M Campbell, G M Cochrane, R Langton Hewer, L S Illis, C Ellis, P Kennedy, N Lawton, D Stephens, A Turner and $G$ Wakefield for allowing us to study patients under their care, to Dr M Sedgewick who made the diagnostic index their care, to Dr M Sedgewick who made the diagnostic index
of the neurophysiology department of the Wessex Neurological of the neurophysiology department of the Wessex Neurological
Centre available to us, to the many general practitioners without Centre available to us, to the many general practitioners without
whose cooperation the study would not have been possible, to whose cooperation the study would not have been possible, to
Mrs M Mitchell, who carried out all the interviews for this study, and to the Motor Neuron Disease Association for allowing us access to their records and for a grant towards the interviewer's travelling expenses. We thank Professor D J P Barker and Dr A Hall for their advice and encouragement.

1 Martyn CN, Barker DJP, Osmond C. Motoneuron disease and past poliomyelitis in England and Wales. Lancet and past poliom

2 Lilienfeld DE, Chan E, Ehland J, et al. Rising mortality from motoneuron disease in the USA, 1962-1984. Lancet 1989;i:710-3.

3 Flaten TP. Rising mortality from motoneuron disease. Lancet 1989;i:1018-9.

4 Durrleman S, Alperovitch A. Increasing trend of ALS in France and elsewhere: are the changes real? Neurology 1989;39:768-73.

5 Zilka KJ. Discussion on motor neurone disease. Proc $R$ Soc Med 1962;55:1028-31.

6 Poskanzer DC, Cantor HM, Kaplan GS. The frequency of preceding poliomyelitis in amyotrophic lateral sclerosis. In:
Norris FH, Kurland LT, eds. Motor neuron disease. New Norris FH, Kurland LT, eds. Motor
York: Grune and Stratton, 1969.

7 Martyn CN. Poliovirus and motor neuron disease. 7 Neurol 1990;237:336-8.

8 Bodian D. Poliomyelitis. In: Minckler J, ed. Pathology of the nervous system, vol III. New York: McGraw-Hill, 1977; 2323-43.

9 Roebuck $M$, Chamberlain R. Prevalence of antibodies to poliovirus in 1978 in subjects aged $0-88$ years. $\mathrm{Br} \mathrm{Med} \mathcal{f}$ 1982;284:697-700.

10 Backett EM. Social patterns of antibody to poliovirus. Lancet 1957;i:778-83.

11 MacLeod RC, MacGregor LG, Larminie HE, Grist NR. Serological epidemiology of poliomyelitis in central Scotland. Scot Med $\mathcal{F}$ 1958;3:76-81.

12 Fox JP, Hall CE. Viruses in families. Littleton, MA: PSG 1980 .

13 Breslow NE, Day NE. Statistical methods in cancer IARC Scientific Publication No. 32. Lyon: International 
Agency for Research in Cancer, 1980.

14 Brimblecombe FSW, Cruickshank R, Masters PL, Reid DD, Stewart GT, Sanderson D. Family studies of respiratory infections. Br Med $\mathcal{f}$ 1958;1:119-28.

15 Visscher BR, Bunnell DH, Detels R. Multiple sclerosis and multiple moves: an etiologic hypothesis. $\mathrm{Am} \mathcal{F}$ Epidemiol 1981;113:140-3.

16 Felmus MT, Patten BM, Swanke L. Antecedent events in amyotrophic lateral sclerosis. Neurology 1976;26:167-72.

17 Gawel M, Zaiwalla Z, Rose FC. Antecedent events in motor neuron disease. $\mathcal{f}$ Neurol Neurosurg Psychiatry 1983;46: 1041-3.

18 Deapen DM, Henderson BE. A case-control study of amyotrophic lateral sclerosis. Am $\mathcal{F}$ Epidemiol 1986;123: 790-9.

19 Roos RP, Viola MV, Wollmann R, Hatch MH, Antel JP. Amyotrophic lateral sclerosis with antecedent poliomyelitis. Arch Neurol 1980;37:312-3.

20 Kott E, Livni E, Zamir R, Kuritzky A. Cell mediated immunity to polio and HLA antigens in amyotrophic lateral sclerosis. Neurology 1979;29:1040-44.

21 Brahic M, Smith RA, Gibbs CJ, Garruto RM, Tourtellotte WW, Cash E. Detection of picornavirus sequences in nervous tissue of amyotrophic lateral sclerosis and control patients. Ann Neurol 1985;18:337-43.

22 Behan PO. Cell mediated immunity in motor neurone disease and poliomyelitis. In: Rose FC, ed. Clinical neuroimmunology, Oxford: Blackwell Scientific Publications, 1979.

23 Bartfeld H, Dham C, Donnenfeld H, et al. Immunological profile of amyotrophic lateral sclerosis patients and their cell-mediated immune responses to viral and CNS cell-mediated immune responses to viral

24 antigens. Clin Exp Immunol 1982;48:137-47. neurones in the human lumbosacral cord throughout life. neurones in the human lumb.
$f$ Neurol $S c i 1977 ; 34: 213-9$.

25 Bharucha NE, Schoenberg BS, Raven RH, Pickle LW, Byar DP, Mason TJ. Geographic distribution of motor neuron disease and correlation with possible etiologic factors. Neurology 1983;33:911-5.

26 Kurtzke JF, Beebe GW. Epidemiology of amyotrophic lateral sclerosis: 1 . A case-control comparison based on ALS deaths. Neurology 1980;30:453-62.

27 Armon C, Kurland LT, Daube JR, O'Brien PC. Epidemiological correlates of sporadic amyotrophic lateral sclerosis. Neurology 1991;41:1077-84.

\section{Neurological stamp}

\section{The Anatomy Lesson of Dr Tulp by Rembrandt (1606-69)}

Rembrandt's anatomy lesson paintings of Drs Tulp and Deyman hung on either side of the fireplace in the anatomy theatre of the Neiuwe Waag in Amsterdam. Tulp demonstrates the anatomy of the arm muscles to a group of seven-he alone wears a hat to mark the official nature of his demonstration. Some of the listeners are looking at the open page of an anatomical atlas at the feet of the corpse, some at the exposed arm muscles and others at the lecturer.

It was Nicholas Tulp, with other Dutch physicians, who first described cases of beriberi in the Dutch East Indies.

The Anatomy Lesson of Dr Tulp is reproduced on the same set of stamps issued by the Republic of Togo in 1968 which also showed The Anatomy Lesson of Dr Joan Deyman (Stanley Gibbons 597, Scott 647). 